\title{
TO EVALUATE THE EFFECT OF BUPIVACAINE ALONE AND BUPIVACAINE WITH CLONIDINE IN SUPRACLAVICULAR BRACHIAL PLEXUS BLOCK
}

\author{
Swaraj Jyoti Sonowal ${ }^{1}$
}

${ }_{1}^{1}$ Senior Resident, Department of Anaesthesiology, Ram Manohar Lohia Hospital, New Delhi, India.

\begin{abstract}
BACKGROUND
Upper limb surgeries are mostly performed under peripheral blocks, such as the brachial block. Peripheral nerve blocks not only provide intraoperative anaesthesia, but also extend analgesia in the post-operative period without any systemic side-effects. The supraclavicular brachial plexus block provides anaesthesia of the entire upper extremity in the most consistent and time-efficient manner. Supraclavicular brachial plexus blockade provides anaesthesia for surgery of the hand, forearm, elbow and distal humerus.

Aim- The present study was conducted to evaluate the effect of bupivacaine alone and bupivacaine with clonidine in supraclavicular brachial plexus block.
\end{abstract}

\section{MATERIALS AND METHODS}

The prospective, randomised, double-blinded comparative study was conducted with hundred consenting patients between 20 years and 50 years of either sex, which were randomised into 2 groups of fifty each. After enrolment, group assignments were determined by a computer-generated number sequence and were contained in sequentially numbered opaque envelopes to ensure blinding.

Group A ( $\mathrm{n}=50)$ : received $40 \mathrm{~mL}$ of $0.25 \%$ Bupivacaine with $1 \mathrm{~mL}$ of $0.9 \%$ normal saline for brachial plexus block.

Group B ( $\mathrm{n}=50)$ : received $40 \mathrm{~mL}$ of $0.25 \%$ Bupivacaine with $2 \mu \mathrm{g} / \mathrm{kg}$ body weight of Clonidine with normal saline to make a total of $1 \mathrm{~mL}$ as brachial plexus block.

\section{RESULTS}

The results were analysed using appropriate statistical test. The data compiled were analysed with GraphPad InStat@ 3 Statistical Software. For qualitative data, Chi-square test was used. Quantitative data were analysed using student t-test. P-value of 0.05 was considered to be insignificant. Demographic variables (Age, sex, weight in kg) were comparable between the two groups with the P-value remaining insignificant when comparison was done between two groups; age in yrs., sex (M: F), weight in kg, all p-value non-significant and patient's vital parameters (Heart rate, systolic BP, diastolic BP, MAP, SpO2 were all found to be insignificant). The difference in the mean time of onset of sensory and motor block between Group A and Group B was statistically significant, i.e. $\mathrm{p}<0.0001$. The difference in the mean duration of sensory block and motor block between Group A and Group B was statistically significant, i.e. $p<.0001$. The difference in the mean duration of analgesia between Group A and Group B was statistically significant with $\mathrm{p}$-value $<0.0001$. The Ramsay sedation score at various time intervals between the two groups were either equal or with a difference, which was not statistically significant with p-value $>0.05$. No complications or any other adverse events were eminent in either of the groups.

\section{CONCLUSION}

Clonidine ( $2 \mu \mathrm{g} / \mathrm{kg}$ body weight) is superior to bupivacaine alone as an adjunct to local anaesthetic solution when administered into brachial plexus sheath for perioperative analgesia during upper limb surgery.

\section{KEY WORDS}

Supraclavicular Brachial Plexus Block, Bupivacaine, Clonidine.

HOW TO CITE THIS ARTICLE: Sonowal SJ. To evaluate the effect of bupivacaine alone and bupivacaine with clonidine in supraclavicular brachial plexus block. J. Evolution Med. Dent. Sci. 2018;7(38):4137-4142, DOI: 10.14260/jemds/2018/926

\section{BACKGROUND}

Pain is the worst experience for an organism. Word pain is derived from the Latin word "poena" meaning punishment or fine. ${ }^{1,2}$ The International Association for the Study of Pain defines pain as "an unpleasant sensory and emotional experience associated with actual or potential tissue damage, or described in terms of such damage." 3

'Financial or Other Competing Interest': None.

Submission 28-06-2018, Peer Review 31-08-2018,

Acceptance 07-09-2018, Published 17-09-2018.

Corresponding Author:

Swaraj Jyoti Sonowal,

H-14, Third Floor, West Patel Nagar,

New Delhi-110008, India.

E-mail: swarajsonowal@gmail.com

DOI: $10.14260 /$ jemds $/ 2018 / 926$

\section{(c) $(\mathrm{i)})$}

This classification further states that pain is always subjective and that it is a sensation in part of the body. At the same time, it is unpleasant and therefore also has an emotional component. Pain management has become an important matter for medical science. In earlier days, people used to reduce the pain by using drugs like alcohol, opium, hashish and mandragora. Trephination was practiced by Incas and their tradition holds the "Shaman" performing the procedure, chewed cocoa leaves and spitted into the wound, producing the local anaesthetic effect.

Regional anaesthesia and analgesia has the potential to provide excellent operating conditions along with better and prolonged post-operative pain relief with fewer side effects. As a result, it is becoming increasingly popular for ambulatory anaesthesia and for day care patients.

Upper limb surgeries are mostly performed under peripheral blocks such as the brachial block. Peripheral nerve 
blocks not only provide intraoperative anaesthesia, but also extend analgesia in the post-operative period without any systemic side-effects.

The supraclavicular brachial plexus block provides anaesthesia of the entire upper extremity in the most consistent and time-efficient manner. Supraclavicular brachial plexus blockade provides anaesthesia for surgery of the hand, forearm, elbow and distal humerus.

There has always been a search for adjuvant to the regional nerve block with drugs that prolong the duration of post-operative analgesia, but with lesser adverse effects.

Alpha- 2 adrenergic receptor agonists have been the focus of interest for their sedative, analgesic, perioperative sympatholytic and cardiovascular stabilising effects with reduced anaesthetic requirements. Furthermore, various methods of administration such as epidural, intrathecal and peripheral injections have been tried either alone or in combination with another drug to prolong and intensify the anaesthesia.

This study was undertaken to evaluate efficacy and potency of bupivacaine alone and bupivacaine plus clonidine in supraclavicular brachial plexus block for onset and duration of sensory and motor block, haemodynamic stability, duration of effective analgesia including postoperative analgesia and any adverse effects in patients undergoing upper limb surgeries.

\section{MATERIALS AND METHODS}

This was a prospective, randomised, double-blinded comparative study, which was conducted under the Department of Anaesthesiology and Critical Care, Silchar Medical College and Hospital, Silchar after approval from the Hospital Ethics Committee and after obtaining patient's attendant's informed consent. The study was carried out on 100 patients of ASA Grade I and II scheduled for upper limb surgery. Sample size was taken for convenience. After enrolment, group assignments were determined by a computer-generated number sequence and were contained in sequentially numbered opaque envelopes to ensure blindingGroup A ( $\mathbf{n = 5 0 ) : ~ R e c e i v e d ~} 40 \mathrm{~mL}$ of $0.25 \%$ Bupivacaine with $1 \mathrm{~mL}$ of $0.9 \%$ normal saline for brachial plexus block.

Group B (n= 50): Received $40 \mathrm{~mL}$ of $0.25 \%$ Bupivacaine with $2 \mu \mathrm{g} / \mathrm{kg}$ body weight of Clonidine with normal saline to make a total of $1 \mathrm{~mL}$ as brachial plexus block.

\section{Inclusion Criteria}

- $\quad$ Patients belonging to ASA Grade I and II.

- Patients of both sexes between the age group 20 and 50 years.

- $\quad$ Patients scheduled for elective upper limb surgeries.

\section{Exclusion Criteria}

- Patient's refusal.

- Patients having history of hypersensitivity to local anaesthetics.

- $\quad$ Patients with skin sepsis in supraclavicular area, patients with pre-existing neurological disorders.

\section{Preoperative Preparations}

All the patients underwent thorough pre-anaesthetic evaluation on the day prior to surgery. All systems were examined including airway and the surface anatomy, where the block was to be given. Basic laboratory investigations were conducted including complete haemogram, urine analysis, blood sugar, kidney function test and whenever needed chest x-ray and electrocardiogram. The anaesthetic procedure to be carried out was explained. Patients were reassured to alleviate their anxieties. A written informed consent was taken. They were educated regarding the visual analogue scale. All the patients were fasted overnight. All of them received oral tablet alprazolam $0.5 \mathrm{mg}$ and tablet ranitidine $150 \mathrm{mg}$ the night before surgery.

\section{Plan of Study}

Supraclavicular brachial plexus block was carried out as an elective procedure on the patients undergoing upper limb surgery. It was a prospective, randomised, double-blind study with hundred consenting patients between 20 years and 50 years of either sex divided into 2 groups of fifty each. All drug solutions were prepared by an anaesthesiologist not involved in administration of anaesthesia, patient care and data collection.

Group A (n= 50): Received $40 \mathrm{~mL}$ of $0.25 \%$ Bupivacaine with $1 \mathrm{~mL}$ of $0.9 \%$ normal saline for brachial plexus block.

Group B (n= 50): Received $40 \mathrm{~mL}$ of $0.25 \%$ Bupivacaine with $2 \mu \mathrm{g} / \mathrm{kg}$ body weight of Clonidine with normal saline to make a total of $1 \mathrm{~mL}$ as brachial plexus block.

Intravenous access was obtained in the limb opposite to that undergoing surgery with $18-\mathrm{G}$ cannula. Injection bupivacaine of $0.5 \%$ was diluted with distilled water to make $0.25 \%$ bupivacaine of volume $40 \mathrm{~mL}$, taking care not to exceed a total drug dose of $2 \mathrm{mg} / \mathrm{kg}$ of bupivacaine. To this local anaesthetic, the study drug was added. Before the start of the procedure patient's pulse rate, blood pressure, respiratory rate and oxygen saturation were recorded. The patient was placed in supine position with the head turned away from the side to be blocked. The arm to be anaesthetised was adducted and the hand extended along the side towards the ipsilateral knee as far as possible. A small roll of towel was placed between the shoulder blades to make the plexus taut. Using classic technique approach, the midpoint of the clavicle was identified and marked. The posterior border of the sternocleidomastoid can be palpated easily when the patient raises the head slightly. Palpating the belly of the anterior scalene muscle and moving towards interscalene groove with the fingers, a mark was made at approximately 1.5 to $2.0 \mathrm{~cm}$ posterior to the midpoint of the clavicle. This was the point of entry. By palpating the subclavian artery at this site, landmark was confirmed. After appropriate preparation and injection of a skin wheal with local anaesthetic, the Stimuplex needle was connected with the nerve stimulator with the current output set at $1.0 \mathrm{~mA}$ and repeat twitch mode selected by the assistant under the guidance of an anaesthetist. The needle was inserted in a caudad slightly medial and posterior direction. On needle insertion, a twitch of the upper trunk (shoulder) was considered as the evidence of the needle approaching the brachial plexus. Wrist flexion and extension of the fingers were taken as acceptable responses and the current was gradually reduced between 0.2 and $0.5 \mathrm{~mA}$, whereby maintaining the visible twitches. The total volume of the anaesthetic solution was injected at an incremental dose of $4 \mathrm{~mL}$ each, preceded by negative aspiration for air or blood. 
After confirming negative aspiration, appropriate drugs were injected. Group A received $40 \mathrm{~mL}$ of $0.25 \%$ Bupivacaine and 1 $\mathrm{mL}$ of $0.9 \%$ normal saline. Group B received $40 \mathrm{~mL}$ of $0.25 \%$ Bupivacaine and Clonidine $2 \mu \mathrm{g} / \mathrm{kg}$ body weight.

\section{Study Parameters}

1. The onset time of sensory blockade, defined as time between injection and total abolition of pinprick response was evaluated in 4 nerve areas (Median, Ulnar, Radial and Musculocutaneous) at every 3 minutes until 30 minutes after the injection. The block was judged to have failed if anaesthesia was not present in 2 or more peripheral nerve distributions and such patients were excluded from the study.

2. For motor block, the inability to flex or extend the following joints: musculocutaneous nerve (Flex Elbow), median nerve (Flex Distal Interphalangeal Joint of $2^{\text {nd }}$ Finger), radial nerve (Extend Wrist), ulnar nerve (Abduct $3^{\text {rd }}$ and $4^{\text {th }}$ fingers) was tested. Time of onset of motor block, defined as the time between injection of local anaesthetic and inability to move the joints was evaluated every 5 minutes and time to block at least two major nerves was noted. Hollmen scale was used to assess both sensory and motor blockade.

3. The duration of sensory blockade, defined as the time between onset of action and return of pinprick response was assessed every 30 minutes in at least 3 major nerve territories.

4. The duration of analgesia, defined as the time between onset of action and onset of pain, was the time when patients received the first dose of rescue analgesic. Supplemental analgesia was given in the form of intramuscular injection of Diclofenac sodium 50 to 75 mg when visual analogue scale score was more than 4 .

5. The duration of motor blockade, defined as the time elapsed between injection of drug and complete return of muscle power in at least 2 major nerve distributions was assessed every 30 minutes.

During surgery pulse, non-invasive blood pressure and peripheral oxygen saturation through pulse oximetry were monitored. Respiratory rate was also monitored. These parameters were monitored every 5 minutes for the first 30 minutes and then every 15 minutes till 2 hours and then hourly till 12 hours. No sedatives were given during surgery and degree of sedation was assessed immediately after giving the block which was considered as 0 hours and then every 5 minutes for the first 30 minutes and then every 15 minutes till 2 hours and then hourly till 12 hours.

The duration of surgery for both the groups was noted. Symptoms such as nausea, vomiting, drowsiness and other adverse effects/ complications were also monitored-

- After establishment of adequate level of block, surgery was started and time of beginning of surgery was noted.

- Intravenous fluids were administered in dose depending on the weight of patient and adjusted according to surgery.

- The duration of effective analgesia was defined as time from injection to complaint of unbearable pain.

Numerical data were presented as mean \pm SD and categorical data as proportions (\%). The qualitative data was expressed by Chi-square test and Student's t-test was used to examine the degree of significance. For statistical analysis, SPSS software version 25 was used. $P$ value was calculated and $\mathrm{P}<0.05$ was considered to be statistically significant.

\section{RESULTS}

A prospective, randomised, double-blinded comparative study consisting of 50 patients in Group A ( Bupivacaine alone) and 50 patients in Group B (Bupivacaine plus Clonidine) is undertaken to study the change in pattern of haemodynamics, pain score by VAS, duration of analgesia, duration of sensory and motor blockade and side effects.

There were no statistical differences according to demographic data (Age, sex, weight). P-value for age- 0.8375 , sex 0.6820 , weight- 0.6379 being non-significant ( $p>0.05$ ).

The difference in the meantime of onset between Group A and Group B was statistically significant, i.e. p $<0.0001$.

\begin{tabular}{|c|c|c|c|}
\hline & $\begin{array}{c}\text { Group A } \\
(\mathbf{n = 5 0 )}\end{array}$ & $\begin{array}{c}\text { Group B } \\
(\mathbf{n}=\mathbf{5 0})\end{array}$ & \multirow{2}{*}{ P value } \\
\cline { 2 - 3 } & Mean \pm SD & Mean \pm SD & \\
\hline Time of Onset (Min) & $12.48 \pm 1.94$ & $7.74 \pm 1.44$ & $<0.0001$ \\
\hline
\end{tabular}

The difference in the meantime of onset between Group A and Group B was statistically significant, i.e. $p<0.0001$.

\begin{tabular}{|c|c|c|c|}
\hline & $\begin{array}{c}\text { Group A } \\
(\mathbf{n}=\mathbf{5 0})\end{array}$ & $\begin{array}{c}\text { Group B } \\
(\mathbf{n = 5 0 )}\end{array}$ & \multirow{2}{*}{ P value } \\
\cline { 2 - 3 } & Mean \pm SD & Mean \pm SD & \\
\hline $\begin{array}{c}\text { Time of } \\
\text { Onset (Min) }\end{array}$ & $18.88 \pm 2.97$ & $13.56 \pm 1.55$ & $<0.0001$ \\
\hline
\end{tabular}

The difference in the mean duration of sensory block between Group A and Group B was statistically significant, i.e. $\mathrm{p}<0.0001$.

\begin{tabular}{|c|c|c|c|c|}
\hline $\begin{array}{c}\text { Duration } \\
\text { of Sensory } \\
\text { Block (Min) }\end{array}$ & $\begin{array}{c}\text { Group A (n=50) } \\
\text { No. of } \\
\text { Patients }\end{array}$ & $\begin{array}{c}\text { Percent } \\
\text { (\%) }\end{array}$ & $\begin{array}{c}\text { Go. of } \\
\text { Patients }\end{array}$ & $\begin{array}{c}\text { Percent } \\
\text { (\%) }\end{array}$ \\
\hline $240-320$ & 25 & 50 & 0 & 0 \\
\hline $321-400$ & 24 & 48 & 11 & 22 \\
\hline $401-480$ & 1 & 2 & 28 & 56 \\
\hline $481-560$ & 0 & 0 & 11 & 22 \\
\hline Total & $\mathbf{5 0}$ & $\mathbf{1 0 0}$ & $\mathbf{5 0}$ & $\mathbf{1 0 0}$ \\
\hline Mean \pm SD & $324.6 \pm 38.34$ & $449.2 \pm 45.57$ \\
\hline \multicolumn{5}{|c|}{$\mathrm{P}<0.0001$} \\
\hline
\end{tabular}

The difference in the mean duration of motor block between Group A and Group B was statistically significant, i.e. $\mathrm{p}<0.0001$.

\begin{tabular}{|c|c|c|c|c|}
\hline $\begin{array}{c}\text { Duration of } \\
\text { Motor Block } \\
\text { (Min) }\end{array}$ & $\begin{array}{c}\text { Group A (n=50) } \\
\text { Patients }\end{array}$ & $\begin{array}{c}\text { Group B (n=50) } \\
\text { Po) }\end{array}$ & $\begin{array}{c}\text { No. of } \\
\text { Patients }\end{array}$ & $\begin{array}{c}\text { Percent } \\
\text { (\%) }\end{array}$ \\
\hline $220-320$ & 40 & 80 & 0 & 0 \\
\hline $321-420$ & 10 & 20 & 34 & 68 \\
\hline $421-520$ & 0 & 0 & 16 & 32 \\
\hline Total & $\mathbf{5 0}$ & $\mathbf{1 0 0}$ & $\mathbf{5 0}$ & $\mathbf{1 0 0}$ \\
\hline Mean \pm SD & $\mathbf{2 9 2 . 6 \pm 3 4 . 0 9}$ & $\mathbf{4 0 8 . 2 \pm 4 7 . 7 9}$ \\
\hline \multicolumn{5}{|c|}{$\mathrm{P}<0.0001$} \\
\hline
\end{tabular}


The difference in the mean duration of analgesia between Group A and Group B was statistically significant with $\mathrm{p}$ value $<0.0001$.

\begin{tabular}{|c|c|c|c|c|}
\hline \multirow{2}{*}{$\begin{array}{c}\text { Duration of } \\
\text { Analgesia } \\
\text { (Min) }\end{array}$} & \multicolumn{2}{|c|}{ Group A (n=50) } & \multicolumn{2}{c|}{ Group B (n=50) } \\
\cline { 2 - 5 } & $\begin{array}{c}\text { No. of } \\
\text { Patients }\end{array}$ & $\begin{array}{c}\text { Percent } \\
\text { (\%) }\end{array}$ & $\begin{array}{c}\text { No. of } \\
\text { Patients }\end{array}$ & $\begin{array}{c}\text { Percent } \\
\text { (\%) }\end{array}$ \\
\hline $260-340$ & 35 & 70 & 0 & 0 \\
\hline $341-420$ & 15 & 30 & 14 & 4 \\
\hline $421-500$ & 0 & 0 & 28 & 56 \\
\hline $501-580$ & 0 & 0 & 8 & 16 \\
\hline Total & $\mathbf{5 0}$ & $\mathbf{1 0 0}$ & $\mathbf{5 0}$ & $\mathbf{1 0 0}$ \\
\hline Mean \pm SD & $329.4 \pm 35.88$ & $460.4 \pm 42.42$ \\
\hline \multicolumn{4}{|c|}{$\mathrm{P}<0.0001$} \\
\hline
\end{tabular}

The patients were assessed for post-operative pain using visual analogue scale score. The above chart compares the VAS scores between the two groups with statistically significant difference in VAS score at $4^{\text {th }}, 4.5^{\text {th }}, 5^{\text {th }}, 7^{\text {th }}, 7.5^{\text {th }}$, $8^{\text {th }}, 9.5^{\text {th }}, 10^{\text {th }}$ and $10.5^{\text {th }}$ hours of the study period. At $4^{\text {th }}, 4^{\text {th }}$ and $5^{\text {th }}$ hours of the study period, the VAS score in Group A was more than that in Group B, which was statistically significant. This also corresponds to the duration of analgesia in Group A. And at 7th, $7.5^{\text {th }}$ and $8^{\text {th }}$ hours the VAS score of Group B was more than that of Group A, which was also statistically significant and which corresponded to the duration of analgesia in Group B. And at $9.5^{\text {th }}, 10^{\text {th }}$ and $10.5^{\text {th }}$ hours the VAS score of Group A was more than that of Group B, which was also statistically significant and which corresponded to the second dose of analgesic in Group A.

\begin{tabular}{|c|c|c|c|c|c|}
\hline \multirow{2}{*}{$\begin{array}{c}\text { Study } \\
\text { Period }\end{array}$} & \multicolumn{4}{|c|}{ VAS Score } & \multirow{2}{*}{ P value } \\
\cline { 2 - 5 } & \multicolumn{2}{|c|}{ Group A } & \multicolumn{2}{|c|}{ Group B } & \\
\cline { 2 - 5 } & Mean & SD & Mean & SD & \\
\hline $0.5^{\text {th }} \mathrm{hr}$ & 0.14 & 0.35 & 0.24 & 0.43 & 0.2052 \\
\hline $1^{\text {st }} \mathrm{hr}$ & 0.20 & 0.40 & 0.24 & 0.43 & 0.6312 \\
\hline $1.5^{\text {th }} \mathrm{hr}$ & 0.86 & 0.35 & 0.70 & 0.46 & 0.0532 \\
\hline $2^{\text {th }} \mathrm{hr}$ & 1.22 & 0.41 & 1.10 & 0.41 & 0.1466 \\
\hline $2^{\text {th }} \mathrm{hr}$ & 1.24 & 0.43 & 1.12 & 0.32 & 0.1166 \\
\hline $3^{\text {rd }} \mathrm{hr}$ & 2.10 & 0.36 & 2.00 & 0.34 & 0.1565 \\
\hline $3^{\text {th }} \mathrm{hr}$ & 2.68 & 0.47 & 2.66 & 0.47 & 0.8320 \\
\hline $4^{\text {th }} \mathrm{hr}$ & 3.54 & 0.54 & 2.66 & 0.47 & 0.0001 \\
\hline $4^{\text {th }} \mathrm{hr}$ & 4.48 & 0.50 & 2.66 & 0.47 & 0.0001 \\
\hline $5^{\text {th }} \mathrm{hr}$ & 4.04 & 1.00 & 2.78 & 0.41 & 0.0001 \\
\hline $5^{\text {th }} \mathrm{hr}$ & 3 & 0 & 2.96 & 0.34 & \\
\hline $6^{\text {th }} \mathrm{hr}$ & 3 & 0 & 3.34 & 0.51 & \\
\hline $6^{\text {th }} \mathrm{hr}$ & 3 & 0 & 3.64 & 0.48 & \\
\hline $7^{\text {th }} \mathrm{hr}$ & 3.62 & 0.49 & 4.22 & 0.54 & 0.0001 \\
\hline $7^{\text {th }} \mathrm{hr}$ & 3.64 & 0.48 & 3.96 & 0.66 & 0.0067 \\
\hline $8^{\text {th }} \mathrm{hr}$ & 3.68 & 0.47 & 4.04 & 1.00 & 0.0233 \\
\hline $8^{\text {th }} \mathrm{hr}$ & 4 & & 3.00 & 0.00 & \\
\hline $9^{\text {th }} \mathrm{hr}$ & 4 & & 3.00 & 0.00 & \\
\hline $9^{\text {th }} \mathrm{hr}$ & 4.42 & 0.49 & 3.04 & 0.19 & 0.0001 \\
\hline $1^{\text {th }} \mathrm{hr}$ & 4.16 & 0.99 & 3.14 & 0.35 & 0.0001 \\
\hline $10^{\text {th }} \mathrm{hr}$ & 3.10 & 0.30 & 3.60 & 0.49 & 0.0001 \\
\hline $11^{\text {th }} \mathrm{hr}$ & 3.42 & 0.49 & 3.60 & 0.53 & 0.0810 \\
\hline $11.5^{\text {th }} \mathrm{hr}$ & 4.18 & 0.38 & 4.12 & 0.43 & 0.4615 \\
\hline $1^{\text {th }} \mathrm{hr}$ & 3.84 & 0.42 & 3.76 & 0.55 & 0.4157 \\
\hline & & & & & \\
\hline
\end{tabular}

The Ramsay sedation score at various time intervals between the two groups were either equal or with a difference, which was not statistically significant with $p$ value $>0.05$.

\begin{tabular}{|c|c|c|c|c|}
\hline \multirow{2}{*}{$\begin{array}{c}\text { No. of Analgesic } \\
\text { Doses }\end{array}$} & \multicolumn{2}{|c|}{ Group A } & \multicolumn{2}{c|}{ Group B } \\
\cline { 2 - 5 } & $\begin{array}{c}\text { No. of } \\
\text { Patients }\end{array}$ & $\mathbf{\%}$ & $\begin{array}{c}\text { No. of } \\
\text { Patients }\end{array}$ & $\%$ \\
\hline 1 & 0 & 0 & 42 & 84 \\
\hline 2 & 41 & 82 & 8 & 16 \\
\hline 3 & 9 & 18 & 0 & 0 \\
\hline Total No. of Patients & 50 & 100 & 50 & 100 \\
\hline $\begin{array}{c}\text { Total No. of } \\
\text { Analgesic Doses } \\
\text { Consumed }\end{array}$ & \multicolumn{2}{|c|}{58} \\
\hline Mean \pm SD & 109 & \multicolumn{2}{|c|}{} \\
\hline \multicolumn{3}{|c|}{$2.18 \pm 0.39$} & $1.16 \pm 0.37$ \\
\hline
\end{tabular}

The above chart shows the difference in the requirement of rescue analgesics between the two groups in the first 12 hours post-operatively. Most of the patients in Group A required 2 doses of analgesics in the first 12 hours postoperatively, whereas most patients in Group B required only 1 dose of analgesic in the first 12 hours post-operatively. One dose of analgesic was not sufficient for any patient in Group A and none of the patients in Group B required 3 doses of analgesics in the first 12 hours post-operatively. Total number of analgesic doses consumed by Group A was 109 with a mean and standard deviation of $2.34 \pm 0.48$ and total number of analgesic doses consumed by Group B was 58 with a mean and standard deviation of $1.26 \pm 0.44$. The difference was statistically significant $(\mathrm{P}<0.0001)$.

\section{DISCUSSION}

The concept of pre-emptive analgesia was introduced by Woolf who demonstrated through experimental studies that post injury pain hypersensitivity results via central mechanism. Intense or repeated noxious stimuli causes release of excitatory amino acids, such as glutamate and aspartate in the dorsal horn. The action of the excitatory amino acids are mediated by NMDA and non-NMDA receptors. Activation of NMDA receptors leads to calcium entry into the cell and initiates a series of central sensitisation such as wind-up and long-term potentiation in the spinal cord in the responses of cells to prolonged stimuli.

Central sensitisation has an important role for pain perception and is considered to be one of the mechanisms implicated in the persistence of post-operative pain.

Peripheral nerve block given with local anaesthetic drugs alone produce analgesia only limited to the duration of action of the local anaesthetic. To prolong duration of post-operative analgesia, many agents including alpha 2 agonists have been used. Transmission of input from nociceptors to spinal neurons that project to the brain is mediated by direct monosynaptic contact or by multiple excitatory or inhibitory interneurons. The central terminals of nociceptors contain excitatory transmitters such as glutamate, substance $P$, neurotrophic factors that activate postsynaptic N-methyl-Daspartate, neurokinin and tyrosine kinase receptors, respectively. Concurrent with these events powerful endogenous mechanisms counteracting pain unfold both in the periphery and in the central nervous system.

Transmission of input from nociceptors to spinal neurons that project to the brain is mediated by direct monosynaptic contact or by multiple excitatory or inhibitory interneurons. The central terminals of nociceptors contain excitatory transmitters such as glutamate, substance $P$, neurotrophic factors that activate postsynaptic $\mathrm{N}$-methyl-D-aspartate, 
neurokinin and tyrosine kinase receptors, respectively. Concurrent with these events powerful endogenous mechanisms counteracting pain unfold both in the periphery and in the central nervous system. Activation of post-synaptic alpha2 receptors in the substantia gelatinosa of the spinal cord is the presumed mechanism by which clonidine produce analgesia. The knowledge of these receptors has been used in the form of various adjuncts administered along with local anaesthetics. These adjuncts may not only prolong the analgesic duration, but also thought to reduce the systemic analgesic consumption as well as their side effects. To prolong perioperative analgesia various adjuncts such as opioids, clonidine, verapamil, neostigmine and tramadol have been tried.

In recent years, the regional techniques of brachial plexus block have gained importance for surgical, diagnostic and therapeutic purposes in interventional pain management. It includes the blocking of the brachial plexus using local anaesthetic agents, where it is most compactly arranged. It provides ideal conditions for surgery, maintains stable haemodynamics intraoperatively, decreases vasospasm, oedema and post-operative pain along with early ambulation, return to work and other advantages of regional techniques which avoids general anaesthesia and its complications. ${ }^{4}$

Addition of clonidine 75 to $150 \mu \mathrm{g}$ to a solution containing tetracaine or bupivacaine and placed in the subarachnoid space prolongs the duration of sensory and motor blockade produced by the local anaesthetic. Clonidine $150 \mu \mathrm{g}$ added to intrathecal bupivacaine seems to be the preferred dose in terms of prolonging the anaesthetic and analgesic effects without introducing unwanted side effects. ${ }^{5}$

So a prospective, randomised, double-blinded, comparative study was carried out to compare the analgesic efficacy of clonidine when used as an adjunct to local anaesthetic in supraclavicular brachial plexus block.

The study was carried out at Silchar Medical College and Hospital, Silchar. Hundred patients belonging to ASA I and II physical status undergoing elective upper limb surgeries were included in the study. Patients were divided into two groups of fifty each-

Group A: $40 \mathrm{~mL}$ of $0.25 \%$ Bupivacaine with $1 \mathrm{~mL}$ of $0.9 \%$ normal saline for brachial plexus block.

Group B: $40 \mathrm{~mL}$ of $0.25 \%$ Bupivacaine with $2 \mu \mathrm{g} / \mathrm{kg}$ body weight of Clonidine with normal saline to make a total of 1 $\mathrm{mL}$ as brachial plexus block.

In our study the mean time of onset of sensory block in Group A was $12.48 \pm 1.94$ minutes, while in Group B it was $7.74 \pm 1.44$ minutes. The difference in the mean time of onset between Group A and Group B was statistically significant, i.e. $\mathrm{p}<0.0001$.

The mean time of onset of motor blockade in Group A was $18.88 \pm 2.97 \mathrm{~min}$, while in Group B it was $13.56 \pm 1.55 \mathrm{~min}$. The difference in the mean time of onset between Group A and Group B was statistically significant, i.e. $p<0.0001$. So there was significant difference in the time of onset of both sensory and motor blockade between the two groups, i.e. the time of onset of sensory and motor block was shortened in Group B compared to Group A, which was similar to the study by Susmita Chakraborty et al, $(2010)^{6}$ and Shivender Singh et al. $(2010){ }^{7}$
The duration of analgesia, defined as the time between onset of action and onset of pain, that is the time when patients received the first dose of rescue analgesic. Supplemental analgesics were given in the form of intramuscular injection diclofenac sodium 50 to $75 \mathrm{mg}$, when visual analogue scale score was more than 4 . The mean duration of analgesia in Group A was $329.4 \pm 35.88$ minutes, while in Group B it was $460.4 \pm 42.42$ minutes. The difference in the mean duration of analgesia between Group A and Group B was statistically significant with $p$ value $<0.0001$. Jean J Eledjam et al (1991) ${ }^{8}$ found prolonged analgesia after addition of clonidine to bupivacaine in supraclavicular brachial plexus block. The duration of analgesia found with clonidine group was $994.2 \pm 34.2$ minutes. This was a significantly longer duration of analgesia compared to our study and the reason might be larger volume ( 40 to $50 \mathrm{~mL}$ ) of bupivacaine used in their study.

In our study, intra-operative and post-operative sedation was assessed using Ramsay sedation score. The postoperative sedation scores were comparable in both groups at different time intervals. None of the patients in both the groups had a Ramsay sedation score of more than 3 during any time interval in the intraoperative period and first 12 hours post-operatively. This finding of ours is in accordance to results obtained by other investigators, where brachial plexus block with clonidine and local anaesthetic mixture did not cause significant changes in sedation level (Jean J Eledjam et al). ${ }^{8}$ No complication or adverse events were observed in either of the groups.

\section{CONCLUSION}

From our study, we conclude that clonidine when administered with bupivacaine is a better option compared to bupivacaine alone, when administered into brachial plexus sheath for providing intra-operative and post-operative analgesia following upper limb surgeries. There is a limitation in our study. The use of ultrasonography guided nerve block helps reduce the total volume of local anaesthetic requirement, but due to the absence of this facility in our institution we could not use this technique.

\section{REFERENCES}

[1] Bonica JJ. History of pain concepts and pain therapy. Seminars in Anaesthesia 1985;4(3):189-207.

[2] Aitkinhead AR, Smith G. Post-operative pain. Textbook of Anaesthesia. $3^{\text {rd }}$ edn. USA: Churchill Livingstone 1996: p. 435-44.

[3] A sample list of frequently used terms. International Association for the Study of Pain Task Force on Taxonomy. In: Merskey NB, edr. Classification of chronic pain. Vol. 2. $2^{\text {nd }}$ edn. Seattle: IASP Press 1994: p. 209-14.

[4] Petrenko AB, Yamakura T, Baba H, et al. The role of NMethyl-D-Aspartate (NMDA) receptors in pain: a review. Anesth Analg 2003;97(4):1108-16.

[5] Strebel S, Gurzeler JA, Schneider MC, et al. Small-dose intrathecal clonidine and isobaric bupivacaine for orthopedic surgery: a dose-response study. Anesth Analg 2004;99(4):1231-8. 
[6] Chakraborty S, Chakrabarti J, Mandal MC, et al. Effect of clonidine as adjuvant in bupivacaine-induced supraclavicular brachial plexus block: a randomized controlled trial. Indian Journal of Pharmacology 2010;42(2):74-7.

[7] Singh S, Aggarwal A. A randomized controlled double blinded prospective study of the efficacy of clonidine added to bupivacaine as compared with bupivacaine alone used in supraclavicular brachial plexus block for upper limb surgeries. Indian J Anaesthesia 2010;54(6):552-7.
[8] Eledjam JJ, Deschodt J, Viel EJ, et al. Brachial plexus block with bupivacaine: effects of added alphaadrenergic agonists: comparison between clonidine and epinephrine. Can J Anaesth 1991;38(7):870-5. 